\title{
Sự dịch chuyển lên phía bắc của dao động nội mùa và cơ chế dao động nội mùa của lượng mưa tại Bắc Bộ và Nam Bộ
}

\author{
Bùi Minh Tuân", Nguyễn Minh Trường, Vũ Thanh Hằng, Công Thanh \\ Khoa Khi tuợng Thủy văn và Hải duoong học, Truờng Đại học Khoa học Tụ nhiên, ĐHQGHN, \\ 334 Nguyễn Trãi, Thanh Xuân, Hà Nọi, Việt Nam \\ Nhận ngày 08 tháng 8 năm 2016 \\ Chỉnh sửa ngày 26 tháng 8 năm 2016; Chấp nhận đăng ngày 16 tháng 12 năm 2016
}

\begin{abstract}
Tóm tắt: Trong nghiên cứu này, sự dịch chuyển lên phía bắc của dao động nội mùa và cơ chế dao động nội mùa của trường mưa quan trắc tại Bắc Bộ và Nam Bộ được tính toán dựa trên số liệu tái phân tích của ECMWF và số liệu mưa quan trắc ngày trong giai đoạn 1981 đến 2009. Kết quả cho thấy Việt Nam chịu tác động rõ ràng của sự dịch chuyển lên phía bắc của dao động nội mùa trong mùa hè. Sự dịch chuyển này là thành phần chính nắm giữ thông tin quan trọng nhất của dao động nội mùa của trường gió vĩ hướng ở khu vực Đông Nam Á và Nam Á. Dao động này là nguyên nhân gây ra các giai đoạn khô và ẩm ướt luân phiên tại Bắc Bộ và Nam Bộ với chu kì từ 30 đến 40 ngày. Tuy nhiên có sự khác nhau rất lớn trong đặc trưng hoàn lưu quy mô lớn gây ra mưa tại hai khu vực Bắc Bộ và Nam Bộ. Cụ thể, ẩm từ khu vực nhiệt đới Tây Thái Bình Dương và vịnh Bengal là nguồn cung cấp chính cho dao động nội mùa của đối lưu ở Bắc Bộ, ngược lại, đối lưu tại Nam Bộ chỉ được cung cấp bởi ẩm được đưa tới từ khu vực nhiệt đới Ấn Độ Dương.
\end{abstract}

Tù khóa: Dao động nội mùa, lọc Lanczos, lượng mưa.

\section{Mở đầu}

Dao động nội mùa (ISO) là một trong những dao động khí quyển quan trọng nhất ở vùng nhiệt đới. Dao động này tác động nhiều nhất đến thời tiết của các quốc gia trong khu vực gió mùa Châu Á, trong đó có Việt Nam. Từ những nghiên cứu đầu tiên của Madden và Jullian (1971) [1], những dao động có chu kì từ 40 đến 50 ngày của trường gió vĩ hướng tại Canton Island được phát hiện. Trong những nghiên cứu sau đó mà cấu trúc không gian của ISO được chỉ ra dựa trên trường khí áp và gió, Madden và Jullian (1972) [2] thấy rằng dao

\footnotetext{
"Tác giả liên hệ. ĐT.: 84-0948544461

Email: tuanbuiminh88@gmail.com
}

động này có quy mô toàn cầu và về cơ bản chúng dịch chuyển sang phía đông với số sóng vĩ hướng -1 .

Trong khi sự dịch chuyển sang phía đông của ISO chủ yếu được quan trắc thây trong mùa đông bắc bán cầu thì trong mùa hè bác bán cầu, hướng dịch chuyển chủ đạo của ISO là từ xích đạo đi lên phía bắc tại khu vực Ấn Độ và từ xích đạo lên phía tây bắc tại Tây Thái Bình Dương. Trong những nghiên cứu đầu tiên về ISO của Yasunari $(1979,1980)[3,4]$, tác giả cho thấy có sự dịch chuyển lên phía bắc của mây và đối lưu kết hợp với ISO từ xích đạo lên tới khoảng $30^{\circ} \mathrm{N}$ trong khu vực gió mùa Nam Á. Yasunari lưu ý rằng sự dịch chuyển lên phía bắc được kích hoạt bằng sự dịch chuyển sang 
phía đông của nhiễu động mây đối lưu tại khu vực xích đạo Ấn Độ Dương.

Những nghiên cứu sâu hơn (Krishnamurti và Subrahmanyam 1982 [5], Lorenc 1984 [6], Wang và Rui 1990 [7]) chỉ ra rằng trong mùa hè bắc bán cầu, có hai cực đại mây tại khu vực Ân Độ $\left(70^{\circ}-90^{\circ} \mathrm{E}\right)$, một dọc theo $15^{\circ} \mathrm{N}$ và cực đại còn lại gần xích đạo. Hai cực đại mây này cho thấy đặc trưng theo kiểu "bập bênh", đó là khi cực đại mây này xuất hiện thì cực đại mây kia biến mất. Điều thú vị nhất đó là sự dịch chuyển lên phía bắc của cực đại mây xích đạo có mối liên hệ chặt chẽ với các chu kì xuất hiện và tan rã của cực đại mây tại $15^{\circ} \mathrm{N}$. Phân tích số liệu phát xạ sóng dài (OLR) trong 10 năm (1975-1985), Wang và Rui chia ISO thành 3 loại chính: loại một dịch chuyển sang phía đông $(65 \%)$, loại hai dịch chuyển lên phía bắc $(20 \%)$ và loại ba dịch chuyển sang phía tây $(15 \%)$. Trong tổng số các trường hợp dịch chuyển lên phía bắc, có một nửa là dịch chuyển độc lập lên phía bắc và một nửa kết hợp giữa sự dịch chuyển lên phía bắc và sự dịch chuyển sang phía đông.

Câu hỏi đặt ra đó là điều gì gây nên sự dịch chuyển lên phía bắc của đối lưu trong khu vực gió mùa mùa hè Châu Á. Webster (1983) [8] cho rằng thông lượng bề mặt tới lớp biên có vai trò làm cho khu vực phía trước của đối lưu bất ổn định, dẫn đến sự dịch chuyển lên phía bắc của dải đối lưu. Tuy nhiên, quan trắc cho thấy có sự dịch chuyển mạnh mẽ của ISO diễn ra tại phía bắc của Ân Độ Dương, không phải trên đất liền. Goswami và Shukla (1984) [9] cho rằng tương tác nhiệt-đối lưu có vai trò quan trọng nhất để sinh ra dao động dừng của hai khu vực cực đại mây. Trong lí thuyết của hai tác giả nói trên, sự hoạt động của đối lưu làm tăng độ ổn định tĩnh, tự nó làm ngăn cản sự phát triền đối lưu, trong khi đó bức xạ nhiệt làm giảm sự ổn định tĩnh ẩm và đưa khí quyển tới trạng thái bất ồn định đối lưu mới. Tuy nhiên các tác giả không chỉ rõ cơ chế kết hợp với sự dịch chuyển lên phía bắc của ISO.

Dựa trên kết quả mô phỏng của mô hình, Wang và Xi (1997) [10] đưa ra lí thuyết về sự dịch chuyển của sóng Rossby liên quan đến
ISO. Khi đối lưu dịch chuyển sang phía đông tới trung tâm Thái Bình Dương xích đạo, sự giảm của nhiệt độ mặt nước biển và độ ẩm riêng tạo nên sóng Rossby từ khu vực đối lưu xích đạo, sóng này sau đó hình thành nên "front đối lưu". Front này nghiêng theo hướng tây bắc, từ xích đạo tới $20^{\circ} \mathrm{N}$, tạo nên sự dịch chuyển rất rõ lên phía bắc của tất cả các sóng đang dịch chuyển về phía đông. Tuy nhiên, lí thuyết sóng Rossby này không giải thích được cho trường hợp dịch chuyển độc lập lên phía bắc của ISO.

Tương tác biển-khí quyển là cơ chế được sử dụng nhiều nhất để giải thích cho sự đi lên phía bắc của ISO. Do sự giảm của thông lượng ẩn nhiệt bề mặt (gây ra bởi sự giảm của tốc độ gió) có thể làm tăng nhiệt độ mặt nước biển phía bắc khu vực đối lưu, dẫn đến hội tụ ẩm lớp biên (Kemball-Cook và Wang 2001 [11]). Do đó, vùng khí quyển phía bắc của khu vực đối lưu trở nên bất ổn định và đối lưu sẽ dịch chuyển lên phía bắc. Tuy nhiên, vẫn chưa rõ rằng tương tác biển-khí quyển thật sự giữ vai trò chủ động trong sự dịch chuyển lên phía bắc của ISO hay sự thay đổi của SST chỉ đơn thuần là sự phản ứng lại một cách thụ động do tác động của khí quyển.

Với những nhận xét trên, mục tiêu bước đầu của nghiên này là trả lời câu hỏi ISO hoạt động như thế nào ở khu vực Việt Nam, chúng có dịch chuyển không, và cơ chế vật lý trực tiếp của chúng là gì. Mục 2 tiếp theo sẽ mô tả số liệu sử dụng và các phương pháp để nghiên cứu sự dịch chuyển lên phía bắc của ISO. Mục 3 phân tích kết quả đạt được và cuối cùng là phần kết luận trong Mục 4.

\section{Số liệu và phương pháp}

Trong nghiên cứu này, số liệu tái phân tích của ECMWF (European Centre for MediumRange Weather Forecasts) với độ phân giải $0.75^{\circ} \times 0.75^{\circ}$ và số liệu mưa quan trắc ngày tại 18 trạm của Việt Nam trong giai đoạn 1981 đến 2009 được sử dụng (Hình 1). Phép lọc Lanczos [12] trong dải 20-60 ngày được áp dụng trên cả trường số liệu tái phân tích và trường mưa quan 
trắc để loại bỏ những dao động có chu kì lớn như chu kì liên mùa và chu kì năm, đồng thời loại bỏ cả những dao động có chu kì ngắn như dao động 10 - 20 ngày và các nhiễu động tần số cao. Số liệu sau khi được lọc sẽ được tính toán bằng phương pháp hàm trực giao tự nhiên theo Lorenz [13] để thu được thành phần chính của các dao động nội mùa.

Phương pháp tính hệ số tương quan và hồi quy được sử dụng để tính toán mối liên hệ giữa trường mưa quan trắc và hoàn lưu quy mô lớn. Trong đó, dị thường mưa trung bình tại các khu vực được tính là trung bình giá trị mưa được lọc trong dải 20-60 ngày của tất cả các trạm của khu vực đó.

Để tính toán các đặc trưng quy mô lớn trực tiếp tác động tới sự biến đổi của ISO của mưa quan trắc tại từng khu vực, phương pháp hồi quy được sử dụng. Trong đó:

Trường gió hồi quy bằng tích của hệ số tương quan giữa trường gió hồi quy và độ lêch chuẩn của trường gió.

Hệ số tương quan trễ giữa mưa quan trắc tại Bắc Bộ và Nam Bộ được tính bởi hệ số tương quan giữa trung bình mưa quan trắc được lọc tại Bắc Bộ và Nam Bộ tại các bước thời gian được dịch chuyển một cách tương đối với nhau.

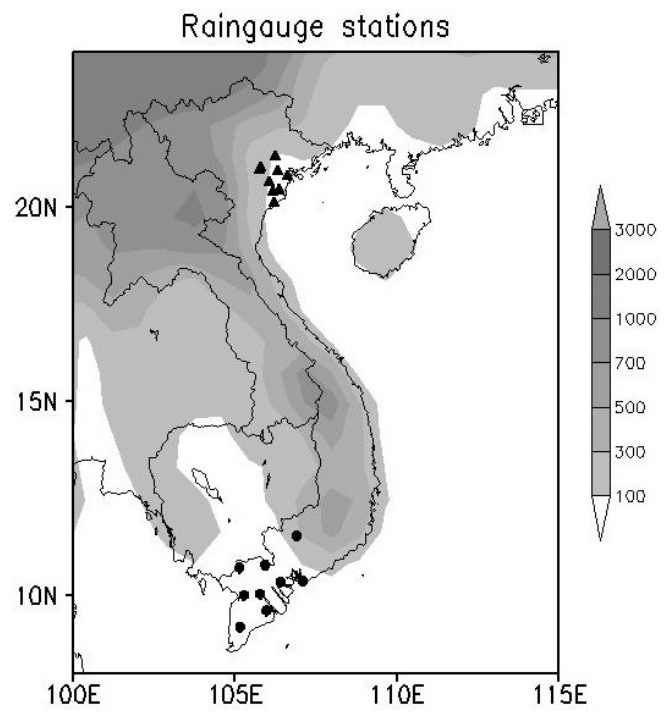

Hình 1. Vị trí các trạm quan trắc ở Bắc Bộ (hình tam giác), Nam Bộ (hình tròn) và độ cao địa hình (vùng mờ).

\section{Một số kết quả và nhận xét}

\subsection{Sụ dịch chuyển lên phía bắc của ISO}

Dựa trên thành phần trực giao đầu tiên của dị thường trường gió vĩ hướng được lọc tại mực $850-\mathrm{hPa}$ trong Hình 2 , có thể thấy ISO có sự dịch chuyển rất rõ lên phía bắc trong suốt mùa hè và sự dịch chuyển chậm xuống phía nam giai đoạn đầu mùa đông bắc bán cầu.
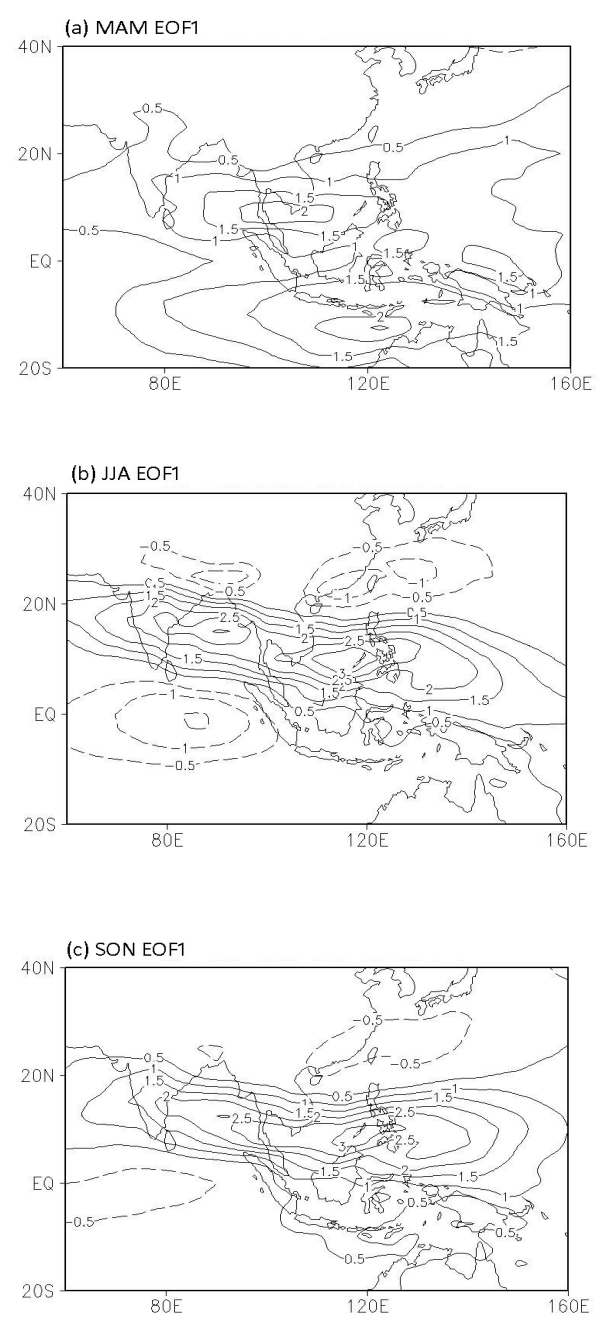

Hình 2. Mode EOF đầu tiên của dị thường trường gió vĩ hướng lọc trong dải 20-60 ngày trong 3 giai đoạn (a) MAM, (b) JJA, (c) SON. Đơn vị m s' 

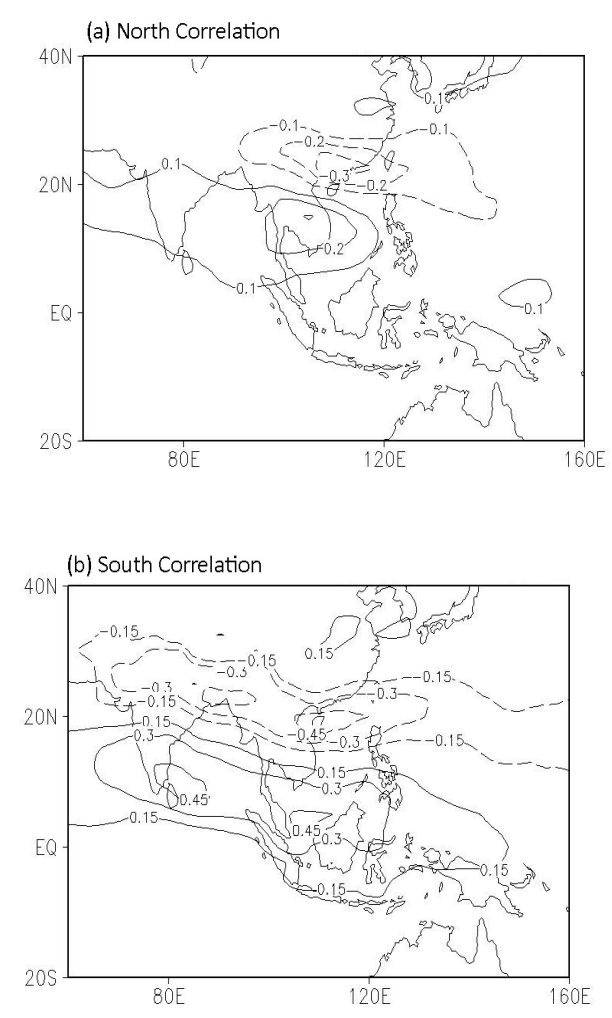

Hình 3. Hệ số tương quan giữa trường mưa quan trắc được lọc trong dải 20 - 60 ngày tại các trạm ở Bắc Bộ $(\mathrm{a})$ và Nam Bộ $(\mathrm{b})$ và trường gió vĩ hướng được lọc trong dải 20 - 60 ngày.

Trong giai đoạn MAM (tháng Ba - Năm, Hình 2a), EOF1 cho thấy hai khu vực dị thường gió vĩ hướng dương với 2 tâm dị thường tại phía nam Việt Nam $(5 \mathrm{oN})$ và phía bắc Australia (-15oS). Trong giai đoạn JJA (tháng Sáu - Tám, Hình 1b), EOF1 cho thấy khu vực dị thường gió vĩ hướng dương chỉ xuất hiện ở bắc bán cầu, với hai tâm dị thường tại Ấn Độ Vịnh Bengal và Tây Thái Bình Dương. Trong khi hình thế của EOF1 trong giai đoạn MAM có hướng song song với xích đạo thì hình thế của EOF1 trong giai đoạn JJA có hướng nghiêng theo chiều tây bắc - đông nam. Điều này cho thấy trong mùa hè, ISO dịch chuyển không đơn thuần chỉ theo hướng bắc mà theo hướng đông bắc. Sự dịch chuyển này tương đối nhanh và rõ nét trong đầu mùa hè bắc bán cầu khi dị thường gió tây nhiêt đới ở nam bán cầu (Hình 2a) hoàn toàn biến mất (Hình 2b).

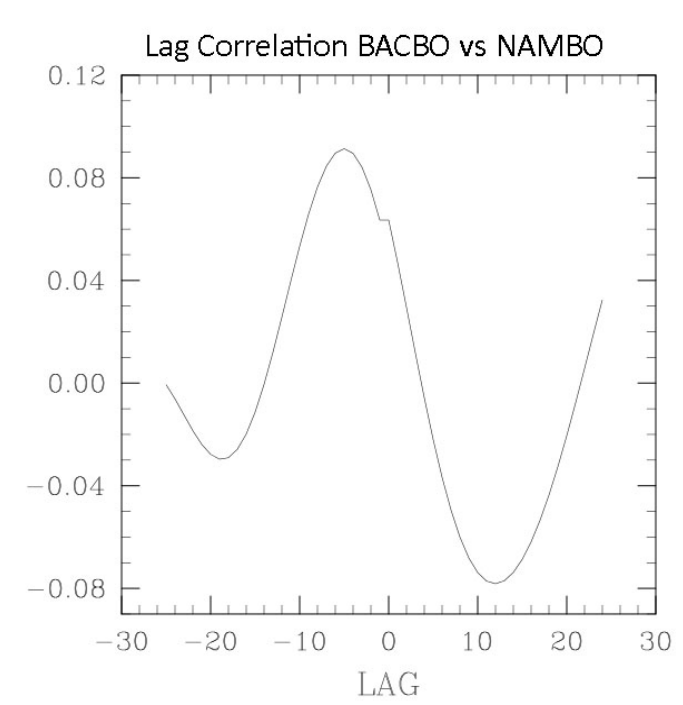

Hình 4. Hệ số tương quan trễ của dị thường trung bình trường mưa quan trắc lọc trong dải 20-60 của các trạm tại Bắc Bộ và Nam Bộ.

Tuy nhiên đến giai đoạn cuối mùa hè, ISO có sự dịch chuyển xuống phía nam nhưng tốc độ chậm hơn nhiều so với việc dịch chuyển lên phía bắc. EOF1 trong giai đoạn SON (tháng Chín - Mười Một, Hình 2c) có hình thế tương tự như EOF1 trong giai đoạn JJA, tuy nhiên trung tâm dị thường dương tại Ấn Độ - Vịnh Bengal gần như biến mất và khu vực bao phủ của dị thường gió vĩ hướng dương thấp hơn khoảng $3^{\circ}$. Sự thay đổi này nhỏ hơn nhiều so với những thay đổi của dị thường dương trong giai đoạn đầu mùa hè (Hình $2 \mathrm{a}, \mathrm{b}$ ).

\subsection{Tác động của ISO tới mưa tại Bắc Bộ và Nam Bọ}

Mối liên hệ giữa ISO của trường gió vĩ hướng và trường mưa quan trắc tại các trạm ở Bắc Bộ và Nam Bộ được thể hiện trong Hình 3. Hình thế của hệ số tương quan trong Hình $3 \mathrm{a}$ và Hình $3 b$ tương đối giống nhau với một cực đại dương ngang qua khu vực Nam Á và một cực đại âm ngang qua khu vực Đông Á cho thấy ISO có tác động tới mưa quan trắc tại cả Bắc Bộ và Nam Bộ. Sự khác nhau chủ yếu giữa hai hình đó là hệ số tương quan trong Hình $3 \mathrm{a}$ nhỏ hơn Hình $3 b$ cho thấy sự tác động yếu hơn của 
ISO tới mưa tại Bắc Bộ, đồng thời trong Hình 3a tồn tại một khu vực có hệ số tương quan dương tại Nhật Bản - Bán đảo Triều Tiên cho thấy sự tác động của yếu tố ngoại nhiệt đới tới mưa tại Bắc Bộ. Mặt khác hình thế của hệ số tương quan trong Hình $3 \mathrm{~b}$ rất giống với hình thế của EOF1 trong giai đoạn JJA (Hình 2b), do đó có thể khẳng định những biến đổi của ISO trong mùa hè là nguyên nhân chính dẫn đến sự thay đổi của lượng mưa tại khu vực Nam Bộ.

\section{(a) North Regression}

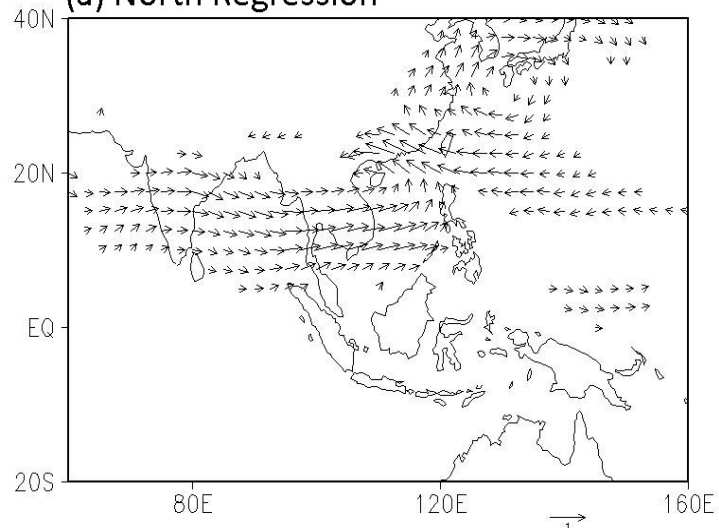

(b) South Regression

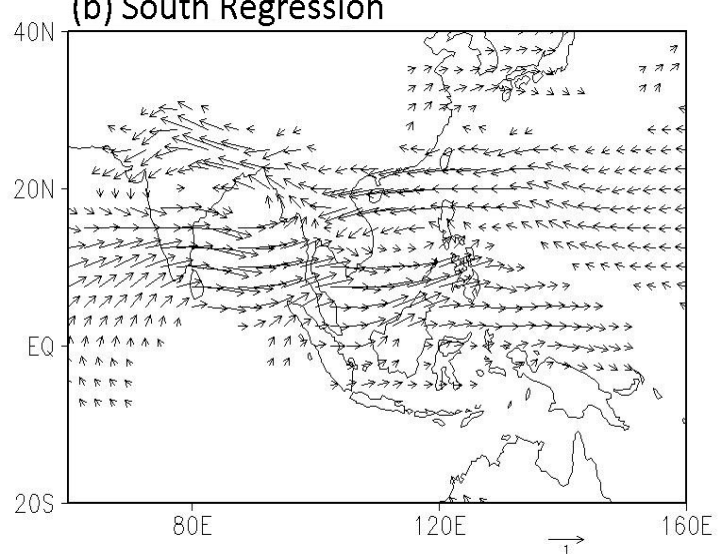

Hình 5. Trường dị thường gió hồi quy từ trường dị thường mưa trung bình quan trắc lọc 20-60 ngày khu vực Bắc Bộ (a) và Nam Bộ (b). Đơn vị $\mathrm{m} \mathrm{s}^{-1}$. Vector gió thể hiện những giá trị gió lớn hơn $0.2 \mathrm{~m} \mathrm{~s}^{-1}$.

Hệ số tương quan trễ trong Hình 4 cho thấy trung bình dị thường trường mưa lọc trong dải
20 - 60 ngày tại Bắc Bộ và Nam Bộ gần như không tương quan với nhau (hệ số tương quan cực đại chỉ đạt 0.08 tại ngày - 6). Sự tương quan yếu này cho thấy mưa tại Bắc Bộ không đơn thuần xuất hiện sau khi mưa xuất hiện tại Nam Bộ do sự dịch chuyển của ISO lên phía bắc. Như vậy, mặc dù có hình thế hệ số tương quan khá giống nhau trong Hình 3 tuy nhiên cơ chế gây mưa tại Bắc Bộ và Nam Bộ lại khác nhau.

\subsection{Sư khác biệt trong co chế gây mua tại Bắc Bộ và Nam Bộ}

Sự khác biệt trong cơ chế gây mưa của ISO tại Bắc Bộ và Nam Bộ được thể hiện qua hồi quy của trường gió theo trường mưa trong Hình 5. Trong Hình 5a, trường gió hồi quy cho thấy có sự xuất hiện của một dị thường xoáy thuận tại Bắc Bộ và một dị thường xoáy nghịch khác ở phía nam Nhật Bản. Hai dị thường xoáy này gần như đối xứng nhau qua đảo Đài Loan đồng thời tăng cường gió đông - đông nam thổi tới Bắc Bộ. Khu vực Nam Á thịnh hành dị thường gió tây nhiệt đới tăng cường cho dị thường xoáy thuận. Do đó có thể nhận định nguyên nhân gây mưa tại Bắc Bộ có sự tương tác giữa hoàn lưu nhiệt đới và hoàn lưu ngoại nhiệt đới, trong đó hoàn lưu xoáy thuận sinh ra có vai trò vận chuyển ẩm từ Tây Thái Bình Dương và Vịnh Bengal, là nguồn cung cấp ẩm chính cho sự phát triển của đối lưu tại Bắc Bộ.

Cơ chế gây mưa tại Nam Bộ do ISO được thể hiện qua trường gió hồi quy theo trường mưa trong Hình $5 b$. Khác với hình thế hoàn lưu quy mô lớn trong Hình $5 \mathrm{a}$, tương tác nhiệt đớingoại nhiệt đới trong Hình $5 \mathrm{~b}$ không được thể hiện rõ nét. Dị thường xoáy nghịch cũng được quan sát thấy tại Nhật Bản tuy nhiên rất yếu, hoàn lưu nhiệt đới được nhận thấy rõ nét tại khu vực Nam Á và Tây Thái Bình Dương với hai dị thường xoáy thuận quy mô lớn nối liền nhau, một tại phía bắc vịnh Bengal, một tại phía nam Biển Đông. Phía nam của hai xoáy thuận này gió tây nhiệt đới được tăng cường rất mạnh, đặc biệt tại khu vực phía nam vịnh Bengal và Biển Đông. Hai xoáy thuận này cắt nhau tại Nam Bộ tạo nên vùng hội tụ gió của hai luồng gió mạnh. 
Khu vực hội tụ gió này được cung cấp lượng ẩm lớn từ Ấn Độ Dương nhiệt đới, do đó là điều kiện lợi để hình thành và phát triển đối lưu sâu tại khu vực này. Nói cách khác, cơ chế gây mưa tại Nam Bộ gần như hoàn toàn do sự chi phối của hoàn lưu nhiệt đới.

\section{Kết luận}

Việt Nam nằm trong khu vực giao tranh của các hệ thống gió mùa lớn, do đó đặc điểm khí hậu của Việt Nam có sự khác biệt rất lớn so với các khu vực khác. Trong mùa hè, mưa tại Việt Nam chịu tác động rất lớn bởi sự dịch chuyển lên phía bắc của ISO. Sự dịch chuyển này được thể hiện rất rõ qua các thành phần trực giao của dị thường trường gió vĩ hướng. Tuy nhiên, tác động của ISO tới mưa quan trắc tại Bắc Bộ và Nam Bộ là hoàn toàn khác biệt, do đó hình thế

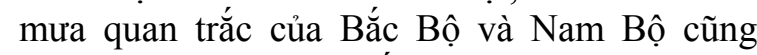
khác nhau. Mưa tại Bắc Bộ được gây bởi sự tương tác giữa hoàn lưu nhiệt đới và hoàn lưu ngoại nhiệt đới, trong khi đó mưa tại Nam Bộ lại chịu sự thống trị hoàn toàn của hoàn lưu nhiệt đới. Ẩm từ khu vực nhiệt đới Tây Thái Bình Dương và vịnh Bengal là nguồn cung cấp chính cho dao động nội mùa của đối lưu ở Bắc Bộ, ngược lại, đối lưu tại Nam Bộ chỉ được cung cấp ẩm được đưa tới từ khu vực nhiệt đới Ấn Độ Dương.

\section{Lời cảm ơn}

Nghiên cứu này được sự hỗ trợ của đề tài NAFOSTED mã số 105.06-2015.03. Số liệu tái phân tích được download từ trang web http://apps.ecmwf.int/datasets/.

\section{Tài liệu tham khảo}

[1] Madden R A, and P Julian, 1971: Detection of a 40-50-day oscillation in the zonal wind in the tropical Pacific. J. Atmos. Sci, 28, 702-708.

[2] Madden R A, 1972: Description of global-scale circulation cells in the Tropics with a 40-50 day period. J. Atmos. Sci, 29, 3138-3158.

[3] Yasunari T, 1979: Cloudiness fluctuations associated with the Northern Hemisphere summer monsoon. J. Meteor. Soc. Japan, 57, 227-242.

[4] Yasunari T, 1980: A quasi-stationary appearance of 30- to 40-day period in the cloudiness fluctuations during the summer monsoon over India. J. Meteor. Soc. Japan, 58, 225-229.

[5] Krishnamurti T N and Subrahmanyam, 1982: The 30-50-day mode at $850 \mathrm{mb}$ during MONEX.J. Atmos. Sci, 39, 2088 - 2095.

[6] Lorenc A C, 1984: The evolution of planetary scale $200 \mathrm{mb}$ divergences during the FGGE year.Quart. J. Roy. Meteor. Soc, 110, 427 - 441.

[7] Wang B and Rui H, 1990: Synoptic climatology of transient tropical intraseasonal convection anomalies: 1975 - 1985. Meteor. Atmos. Phys, 44, 43 - 61.

[8] Webster P J, 1983: Mechanisms of lowfrequency variability: Surface hydrological effects. J. Atmos. Sci, 40, 2110-2124.

[9] Goswami B N and Shukla J, 1984: Quasiperiodic oscillations in a symmetric general circulation model. J. Atmos. Sci, 41, 20-37.

[10] Wang B and Xie X, 1997: A model for the boreal summer intraseasonal oscillation. J. Atmos. Sci, 54,72- 86.

[11] Kemball-Cook S R and Wang B, 2001: Equatorial waves and air - sea interaction in the boreal summer intraseasonal oscillation. J. Climate, 14, 2923 - 2942.

[12] Claude E D, 1979: Lanczos filter in one and two dimensions. J. Appl. Meteor, 1016-1022

[13] Lorenz, E N, 1956: Empiricalorthogonal functions and statistical Weather prediction. Statistical Forecasting Project Rep.1, MIT Department of Meteorology, 49pp. 


\title{
The Northward Propagation of Intraseasonal Oscillation and Mechanisms of Intraseasonal Oscillation of The Observed Rainfall in North and South Vietnam
}

\author{
Bui Minh Tuan, Nguyen Minh Truong, Vu Thanh Hang, Cong Thanh \\ Faculty of Hydrology, Meteorology and Oceanography, VNU University of Science, \\ 334 Nguyen Trai, Thanh Xuan, Hanoi, Vietnam
}

\begin{abstract}
The northward propagation of intraseasonal oscillation (ISO) and mechanisms of intraseasonal oscillation of the observed rainfall in North and South of Vietnam are documented using ECMWF reanalysis and daily observed rainfall data from 1981 to 2009. It is found that Vietnam experiences a clear northward propagation of ISO of the zonal wind in boreal summer. This propagation possesses the largest component of the variation of the zonal wind in the South Asia region and leads to the active and break phase of rainfall in North and South Vietnam with the period of 30-40 days. However, there is a large difference between the mechanism of ISO rainfall in North and South Vietnam. Specifically, moisture from the tropical Western Pacific and Bay of Bengal fuels ISO convection in North Vietnam, whereas convection in South Vietnam energized by moisture from the tropical Indian Ocean only.
\end{abstract}

Keywords: Intraseasonal oscillation, Lanczos filter, monsoon. 